\title{
Numerical analysis of run-up oscillations under dissipative conditions
}

\author{
Andrea Ruju ${ }^{\mathrm{a}, \mathrm{b}}$, Javier L. Lara ${ }^{\mathrm{a}}$, Inigo J. Losada ${ }^{\mathrm{a}}$ \\ ${ }^{a}$ Environmental Hydraulics Institute "IH Cantabria", Universidad de Cantabria, C/ \\ Isabel Torres 15 Parque Cientifico y Tecnologico de Cantabria, 39011 Santander, Spain. \\ ${ }^{b}$ School of Marine Science and Engineering, Plymouth University, Drake Circus, \\ Plymouth, Devon, PL8 4AA, UK
}

\begin{abstract}
This paper presents laboratory and numerical simulations of run-up induced by irregular waves breaking on a gentle-sloping planar beach. The experimental data are well reproduced by a numerical model based on the nonlinear shallow water equations. By extending the incoming wave conditions considered in the laboratory experiments, the model is applied to study the run-up variability under highly energetic incoming conditions. The numerical results support the idea that, for cases characterized by the same incident peak frequency, infragravity run-up increases almost linearly with the offshore significant wave height. Moreover, the most energetic conditions lead to an upper limit of the the swash similarity parameter of about 1.8.
\end{abstract}

Keywords:

Run-up, Gently-sloping beach, Dissipative conditions, Numerical models, Laboratory experiments

\section{Introduction}

Nearshore waves drive oscillations of the shoreward water's edge on the foreshore. The vertical location of the water's edge defines the run-up which results from the sum of a steady and a time-varying component. The steady component is the wave set-up consisting in a superelevation of the mean water level forced by the mean radiation stress gradient within the surf zone

Email address: andrea.ruju@plymouth.ac.uk (Andrea Ruju) 
(Longuet-Higgins and Stewart, 1964). The time-varying component is represented by swash fluctuations forced by that part of wave energy which is not dissipated by breaking processes eventually resulting in a reflection at the shoreline (Miche, 1951).

A large amount of nearshore sediment transport occurs within the swash zone pointing out the importance of this relatively narrow region in the global coastal evolution. Swash hydrodynamics are of great relevance since they drive the sediment exchanges between the surf zone and the subaerial beach (Masselink and Hughes, 1998; Masselink and Puleo, 2006) potentially leading to dune erosion during adverse sea conditions (Ruggiero et al., 2001; Ruessink et al., 2012). In addition, extreme run-up events can generate beach overwash and structure overtopping.

For monochromatic waves, laboratory data are consistent with the Miche (1951) hypothesis which states that swash saturation is expected when the incident wave amplitude increases above the limiting amplitude for nonbreaking standing waves on a slope. Saturation implies that, as a result of dissipation induced by breaking, run-up does not increase with increasing offshore wave height. The onset of swash saturation is expected for a critical value of the non-dimensional parameter $\varepsilon_{s}$ (Miche, 1951). For monochromatic standing waves, Carrier and Greenspan (1958) proposed an analytical solution in which wave breaking occurs when $\varepsilon_{s}=1$. Experimental estimates of the critical value for $\varepsilon_{s}$ range from 1.25 to 3 (Battjes, 1974; Guza and Bowen, 1976; Baldock and Holmes, 1999). Due to wave-wave interactions and energy transfer to low-frequency motion as waves approach the shore, swash oscillations forced by irregular waves are significantly different with respect to monochromatic cases. However, the observations of random wave run-up qualitatively confirm the Miche (1951) saturation hypothesis. Field data suggest that run-up is often saturated at sea-swell frequencies (Guza and Thornton, 1982; Holman and Sallenger, 1985) with saturation potentially extending even at infragravity frequencies during highly energetic storms (Ruessink et al., 1998). Ruggiero et al. (2004) and Senechal et al. (2011) collected video measurements of wave run-up under highly dissipative conditions pointing out that saturation is likely to extend to almost the entire infragravity frequency band.

The infragravity band saturation of run-up appears strictly related to low-frequency energy dissipation in the surf zone. Infragravity energy damping inside the surf zone has been investigated in the last decade by means of field, laboratory and numerical approaches. The laboratory observations 
of Battjes et al. (2004) and van Dongeren et al. (2007) proposed that long wave breaking is the main agent responsible for infragravity wave damping. These findings have been supported by the field observations of de Bakker et al. (2014) who identified infragravity-wave breaking as the dominant dissipation mechanism close to the shoreline. On the other hand, the field work of Thomson et al. (2006) and Henderson et al. (2006) provided evidence of energy transfer from infragravity to incident wave components. Using high spatial resolution numerical data, Ruju et al. (2012) suggested that infragravity energy losses are the result of energy transfer to incident wave components in the outer and middle surf zone, whereas long wave breaking prevails in the inner surf zone. The mechanics of these processes have been questioned by Baldock (2012) who discussed the dissipation of long waves released by short wave breaking. Furthermore, the role played by friction has been analyzed by Henderson and Bowen (2002).

Several field studies have reported high correlation levels between wave energy in deep waters and low-frequency energy in the inner surf and in the swash zone (Guza and Thornton, 1982; Herbers et al., 1995; Ruessink, 1998). Useful empirical parameterizations have been formulated relating run-up to the incoming wave condition, typically including offshore wave height and peak period, and the beach slope (Holman and Sallenger, 1985; Nielsen and Hanslow, 1991; Stockdon et al., 2006). More recently, Guza and Feddersen (2012) addressed the dependence of run-up on the directional and frequency spread by means of numerical modelling. The mentioned work has improved the understanding of long-wave dynamics and run-up, however some issues such as, for example, the low-frequency energy damping in shallow waters and the run-up saturation on the foreshore are still open. In spite of the increased capability of run-up prediction for a wide range of wave conditions and beaches, lack in the knowledge about the prediction of run-up induced by energetic conditions still remains. Significant uncertainties are related to strongly dissipative conditions when saturation is likely to extend over infragravity frequencies potentially leading to an upper limit of wave run-up as hypothesized by Senechal et al. (2011).

It is the objective of this work to study swash oscillations under highly dissipative conditions by means of laboratory and numerical data. Experimental data on swash oscillations are used to validate the numerical model SWASH on a gently-sloping beach. The dependence of swash oscillations induced by energetic incoming sea states is addressed by means of numerical simulations extending the conditions considered in the laboratory experi- 
ments. In particular, the simulated conditions yield the saturation frequency of swash components well below the incident band in order to investigate the run-up behaviour under highly dissipative conditions.

The laboratory experiments are described in section 2. Section 3 introduces the numerical model and provides the model validation. New numerical simulation extending the range of incoming wave height with respect to the laboratory experiments are described and discussed in sections 4 and 5 , respectively. Section 6 points out some conclusions.

\section{Experimental set-up}

\subsection{Wave flume and instrumentation}

The physical experiments included in the GLOBEX project were carried out in the Scheldt flume (The Netherlands). Here, the experimental facilities and the instrumentation relevant for this work are outlined. A more comprehensive description of the laboratory experiments is presented in Ruessink et al. (2013) and other GLOBEX reports mentioned therein.

The Scheldt flume is $110 \mathrm{~m}$ long, $1 \mathrm{~m}$ wide and $1.2 \mathrm{~m}$ high. Waves were generated by a hydraulically-driven piston-type wave maker located at one end of the flume. Glass sidewalls delimit the lateral boundaries of the flume, except in a $7 \mathrm{~m}$ region located in the middle of the flume where concrete sidewalls are present. The fixed bottom profile was made of concrete. A horizontal part of $16.57 \mathrm{~m}$ extended between the wave maker and the toe of the slope, then a beach characterized by a gentle constant slope $\beta$ of 1:80 started reaching the end of the flume. The still water depth during the experiments was set at $0.85 \mathrm{~m}$ in the constant depth section; the undisturbed shoreline therefore lay at $84.57 \mathrm{~m}$ from the mean position of the wave maker.

Free surface displacements were measured using 10 and 12 resistance (RWG) and capacitance (CWG) wave gauges. A capacitance gauge parallel to the beach slope at a height of $0.8 \mathrm{~cm}$ above the bottom detected the run-up oscillations on the beach face. Measured run-up therefore corresponds to the highest position on the beach face where water depth exceeds $0.8 \mathrm{~cm}$.

The target wave maker motion is provided by a second order wave control signal (van Leewen and Klopman, 1996) in order to reproduce bound subharmonic and superharmonic waves suppressing incident free waves generated at the wave maker. Moreover, active reflection compensation was used to absorb outgoing waves and minimize reflection at the wave maker. Wave conditions were irregular but deterministic and therefore reproducible 


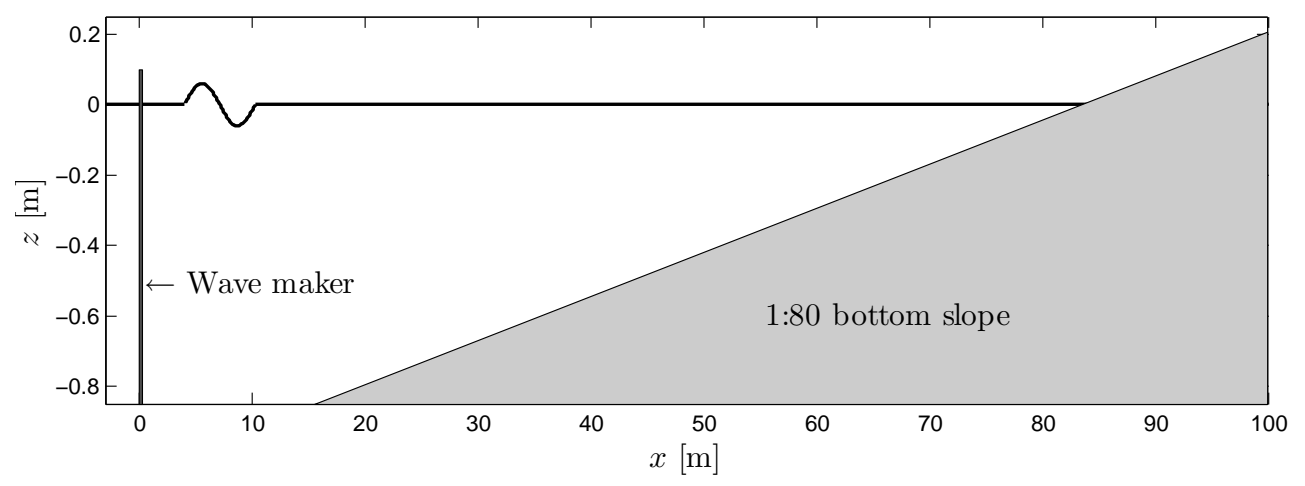

Figure 1: Cross-shore bottom profile and still water level

allowing data to be collected at multiple cross-shore locations by means of experiment repetitions. Each experiment was run ten times leading to a final spatial resolution of wave gauges of $0.37 \mathrm{~m}$ in the most onshore part of the flume for $x>54 \mathrm{~m}$. The most offshore wave gauge, located $7 \mathrm{~m}$ shoreward of the wave paddle, was fixed and used as reference control gauge. As a result of the combined ten runs, 190 locations were achieved for wave gauges. The sampling frequency for the wave gauges and run-up wire was $128 \mathrm{~Hz}$ providing a high temporal resolution. Each experiment was $4500 \mathrm{~s}$ long, in order to achieve a proper value of degrees of freedom for the planned bispectral analysis.

\subsection{Wave characteristics}

Irregular wave conditions matching a JONSWAP spectrum as well as bichromatic and regular waves were conducted during the laboratory experiments. In this work, only the irregular-wave cases are examined. They are characterized by varying peak frequency $\left(f_{p}\right)$, significant wave height $\left(H_{s}\right)$ and peak enhancement factor $(\gamma)$. Cases A1 and A3 represent moderate incoming conditions $\left(H_{s}=0.1 \mathrm{~m}\right)$, whereas the relatively high $H_{s}$ of case A2 provides the most energetic conditions $\left(H_{s}=0.2 \mathrm{~m}\right)$. Case A3 is characterized by a narrow-banded wave spectra $(\gamma=20)$ and a relatively large peak period $\left(T_{p}=1 / f_{p}=2.25 \mathrm{~s}\right)$, usually related to clean swells generated by distant storms. Note that, considering the scale factor of 0.05 , the significant wave height and peak period ranges in prototype are 2-4 $\mathrm{m}$ and 7-10 s, respectively. Table 1 summarizes the three cases with the relative Iribarren 
number $\xi_{0}$ defined as:

$$
\xi_{0}=\frac{\beta}{\sqrt{H_{s 0} / L_{0}}}
$$

where $\beta$ is the beach slope and $H_{s 0}$ and $L_{0}$ stand for the deep water significant wave height and wavelength calculated with linear theory using the peak frequency of the target spectrum.

\begin{tabular}{ccccc}
\hline Case & $H_{s}[\mathrm{~m}]$ & $T_{p}[s]$ & $\gamma$ & $\xi_{0}$ \\
\hline $\mathrm{A} 1$ & 0.1 & 1.58 & 3.3 & 0.08 \\
$\mathrm{~A} 2$ & 0.2 & 2.25 & 3.3 & 0.08 \\
$\mathrm{~A} 3$ & 0.1 & 2.25 & 20 & 0.11 \\
\hline
\end{tabular}

Table 1: Irregular wave cases

\section{Numerical model}

Several studies have shown that numerical approaches based on nonlinear shallow water (NLSW) equations can successfully model swash hydrodynamic processes. Raubenheimer and Guza (1996); Raubenheimer et al. (1995) provided numerical predictions of run-up on a natural beach based on a NLSW-type model initialized with measured free surface elevations and velocities at the seaward boundary located in the inner surf zone. More recently, Barnes et al. (2009) and O'Donoghue et al. (2010) modeled a largescale swash event dambreak-generated by means of a numerical model based on NLSW equations. They found good agreement between measured and predicted run-up depths and velocities; however, O'Donoghue et al. (2010) pointed out that the model was unable to capture the bed shear stress at the time of bore arrival and at the later stages of the backwash.

For the present study, a NLSW-type model is used to simulate the swash oscillations induced by the irregular wave breaking above the sloping bottom. The model is initialized at the mean position of the laboratory wave maker with the aim to simulate the hydrodynamic processes occurring in the whole flume.

\subsection{Model description and set-up}

In this section, we compare model predictions of surf zone and swash zone dynamics with measurements from the experiments. The numerical model 
employed is SWASH (Zijlema et al., 2011) which is based on the nonlinear shallow water (NLSW) equations including non-hydrostatic pressure. Considering the cross-shore direction $x$ only, these equations can be written as

$$
\begin{gathered}
\frac{\partial \eta}{\partial t}+\frac{\partial[(h+\eta) u]}{\partial x}=0 \\
\frac{\partial u}{\partial t}+u \frac{\partial u}{\partial x}+g \frac{\partial \eta}{\partial x}+\frac{1}{h+\eta} \int_{-h}^{\eta} \frac{\partial q}{\partial x} d z+c_{f} \frac{u|u|}{h+\eta}=\frac{1}{h+\eta}\left(\frac{\partial(h+\eta) \tau_{x x}}{\partial x}\right)
\end{gathered}
$$

where $t$ is time, the $x$-axis is located at the sea water level and is positive shoreward, $g$ is acceleration due to gravity, $\eta$ is the free surface elevation measured from the still water level, $h$ is the local still water depth, $u$ denotes the depth-averaged horizontal velocity, $q$ is the non-hydrostatic pressure normalized by the density, $c_{f}$ is the dimensionless bottom friction coefficient and $\tau_{x x}$ is the horizontal turbulent stress term.

The irregular wave cases carried out in the laboratory are simulated with SWASH according to the following setting. Numerical simulations are performed using a horizontal grid size of $2 \mathrm{~cm}$ and 2 equidistant layers in order to resolve the frequency dispersion. In fact, increasing the number of layers, the model improves its frequency dispersion due to the approximation of vertical gradient of the dynamic pressure. It was shown by Zijlema et al. (2011) that the model exhibits accurate wave dispersion up to $k h=3$ (the error is on the order of 1\%) with two equidistant layers for progressive waves. In the model, wave breaking is initiated when the vertical velocity of the free surface $\partial \eta / \partial t$ exceeds a specified ratio of the shallow water wave celerity $\sqrt{g h}$. Here, the default ratio value of 0.6 for the incipient wave breaking is kept:

$$
\frac{\partial \eta}{\partial t}>0.6 \sqrt{g h}
$$

Energy losses induced by breaking within the surf zone are modelled by considering the similarity between broken waves and moving hydraulic jumps.

Previous studies dealing with NLSW modelling of breaking waves on beaches have estimated the bed-induced energy damping by adjusting the friction factor parameter $c_{f}$ (Raubenheimer et al., 1995; O'Donoghue et al., 2010) or the Manning's roughness coefficient $n$ (Zijlema et al., 2011) in order to maximize the agreement between predictions and observations. In the present work, the friction factor is estimated on the basis of the Manning 
coefficient's values for channels provided by Chow (1959). For unfinished concrete, a typical value of the Manning coefficient $n$ is $0.015 \mathrm{~s} / \mathrm{m}^{1 / 3}$ which, assuming that the boundary layer covers the entire swash depth (Puleo and Holland, 2001), allows the calculation of the friction coefficient by means of (see Zijlema et al. (2011))

$$
c_{f}=\frac{n^{2} g}{h^{1 / 3}}
$$

Using a representative water depth $h$ of $1 \mathrm{~cm}$ for the swash zone yields a friction factor $c_{f}=0.011$, which is the spatially uniform value adopted here. This result is also consistent with previous studies (Raubenheimer and Guza, 1996; Hughes et al., 1997; O'Donoghue et al., 2010) reporting friction coefficients on the order of $0.01-0.015$ for natural and laboratory swash zones. It is worth mentioning that the effects of friction are relatively small in the domain except in the swash zone where large bed shear stresses are expected at the run-up tip (Barnes and Baldock, 2010; Kikkert et al., 2011). As a result, run-up is sensitive to the friction factor value chosen.

The component sequences of the primary wave band of the irregular-wave numerical simulations are extracted by means of Fourier transforms of the first order target free surface signal at the mean position of the wave maker. This procedure leads to a total number of primary components in the order of 2000. In order to reproduce the bound long wave field and minimizing the generation of incoming free long waves, the boundary conditions for the numerical model are provided by a second order wave signal in which the bound wave field is given by the sum of the interactions resulting from each pair of wave components (Longuet-Higgins and Stewart, 1960). A weakly reflective condition is adopted at the generating boundary in order to avoid the reflection of outgoing waves.

\subsection{Model validation}

Comparisons between the observed and computed time series of free surface at several spatial location for case A3 are plotted in figure 2. The large $\gamma$ parameter of the JONSWAP spectrum ( $\gamma=20$ for case A3) is associated with well defined and long-period groups constituted by a relatively high number of waves. Waves become steeper and more asymmetric as they approach the shore. Inside the surf zone, wave breaking yields energy dissipation and a change in the wave group structure. In the inner surf zone, as a result of the low Iribarren number, short waves are almost completely damped out by the breaking processes and the wave motion is driven by long-period oscillations 
at group frequency. The commented wave transformation processes induced by the increasing nonlinearity along the flume are satisfactorily reproduced by the model. In particular, the model parameterized onset of wave breaking and the subsequent energy dissipation seem to be in good agreement with laboratory observations (wave height damping in the surf zone is further represented in figure 3). Moreover, the model well captures the wave celerity along the entire flume confirming the effectiveness of the two-layer approach in simulating the effect induced by the dynamic pressure in intermediate waters (Zijlema et al., 2011).

Figure 3 shows the measured and predicted cross-shore evolution of the short- and long-wave components of the significant wave height along the flume up to the point of maximum run-down $(x \approx 83.9 \mathrm{~m})$. The decomposition is carried out in the frequency domain adopting a frequency cutoff $f_{c}$ equal to half the peak frequency:

$$
\begin{aligned}
& H_{s,(l f)}=4 \sqrt{\sum_{f_{1}}^{f_{c}} E(f) d f} \\
& H_{s,(h f)}=4 \sqrt{\sum_{f_{c}}^{f_{2}} E(f) d f}
\end{aligned}
$$

in which $E(f)$ is the free surface energy spectra, $f_{1}=d f$ is the frequency resolution, $f_{c}=f_{p} / 2$ and $f_{2}=3 f_{p}$. High-frequency wave height variation due to the shoaling process is reproduced satisfactorily by the model. The breakpoint location and the wave energy damping within the surf zone are correctly predicted, attesting the effectiveness of the wave breaking parameterization. A small discrepancy can be noticed close to the breakpoint for case A2, where the wave height appears to be slightly overestimated and the damping of short wave height starts more shoreward in the numerical simulation. The low-frequency component of significant wave height is plotted in the right panels of figure 3. The wave height growth due to shoaling and nonlinear energy transfer from sea-swell waves to longer period waves is well simulated by the model. In the surf zone, model predicted long wave dissipation, attested by a considerable decrease of the wave height growth rate within the surf zone (see de Bakker et al. (2013) for further details), agrees well with laboratory measurements. 


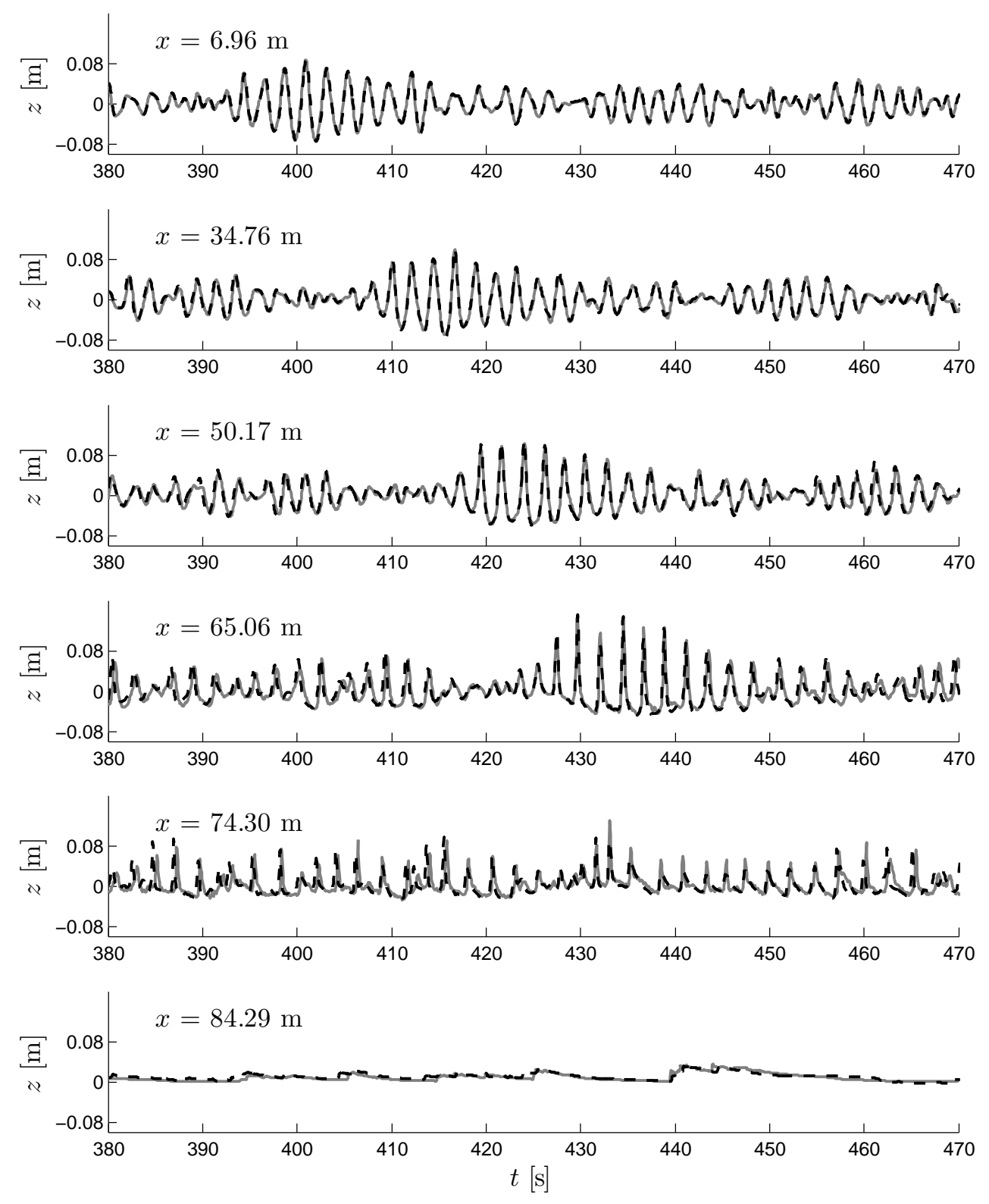

Figure 2: Comparisons between the observed (grey solid line) and simulated (black dashed line) free surface time series at different cross shore locations. Case A3.

In order to quantitatively evaluate the model performance in reproducing 

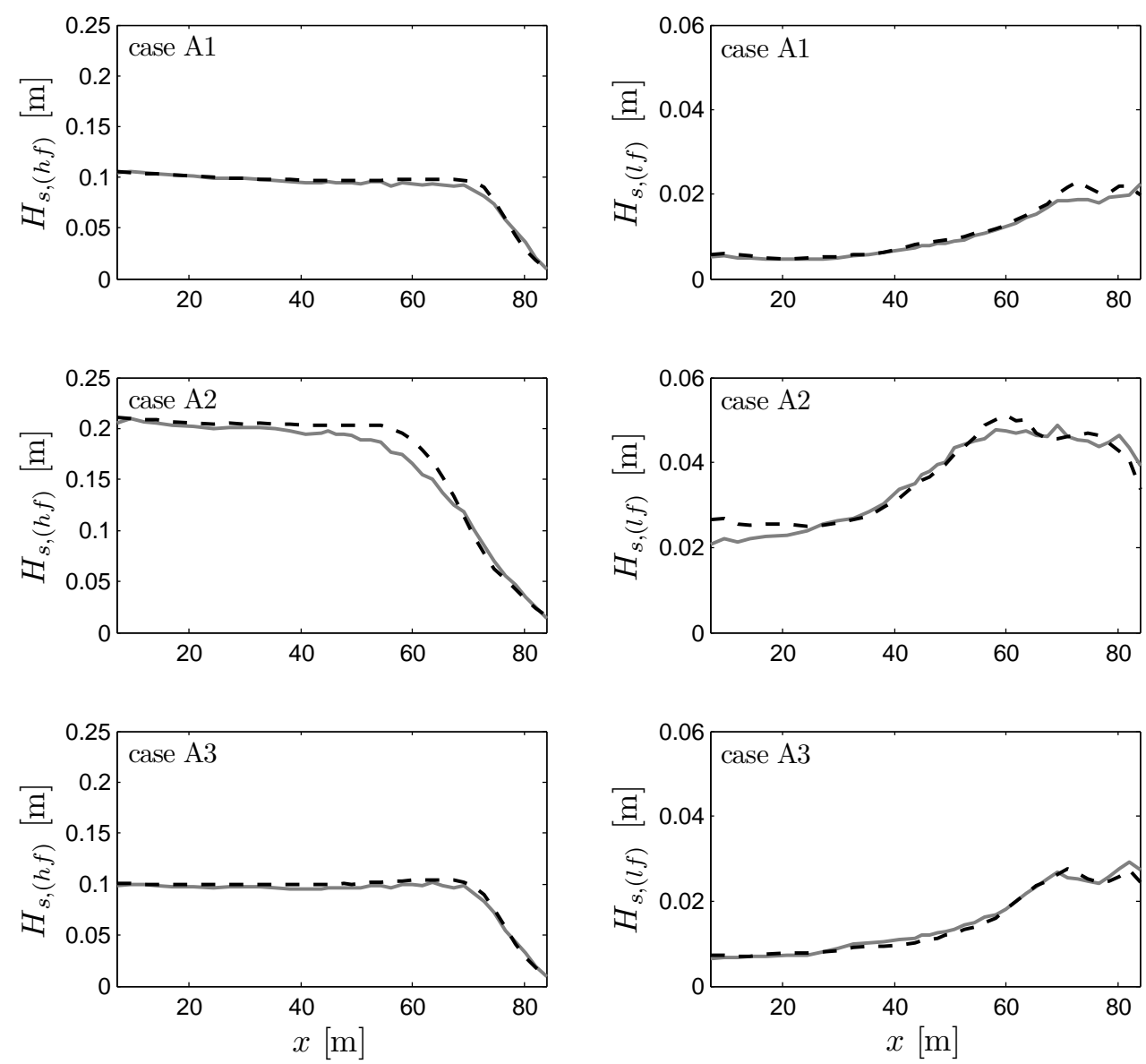

Figure 3: Comparisons between the measured (grey solid line) and simulated (black dashed line) cross-shore variation of significant wave height. Left panels: high-frequency part; right panels: low-frequency part.

the observed evolution of significant wave height, we calculate the relative errors as the difference between the predicted $H_{m}$ and the experimental values $H_{l}$, divided by the experimental values:

$$
E(\%)=\left|\frac{H_{m}-H_{l}}{H_{l}}\right| \cdot 100
$$

The errors are expressed in percentages and they are strictly positive because of the modulus operator. The predicted high-frequency and low-frequency 
significant wave height present a mean (averaged over the whole flume) relative error of $5.1 \%$ and $6.3 \%$, respectively. The highest errors for the highfrequency band are observed in the outer surf zone and they reach values in the order of $15 \%$ (a maximum error of $16 \%$ is found for case A2 at $x=62$ $\mathrm{m})$.

The comparison of measured and computed cross-shore evolution of mean set-up is illustrated in figure 4. The model-predicted set-up evolution is generally in good agreement with observations. The predicted set-up for case A2 is slightly larger than that observed during the experiments; this is likely to be related with the overestimation of significant wave height in the outer surf zone for the same case. In general terms, figures 3 and 4 show an overall good agreement between model predictions and observations of the mean parameters related to wave motion along the flume.
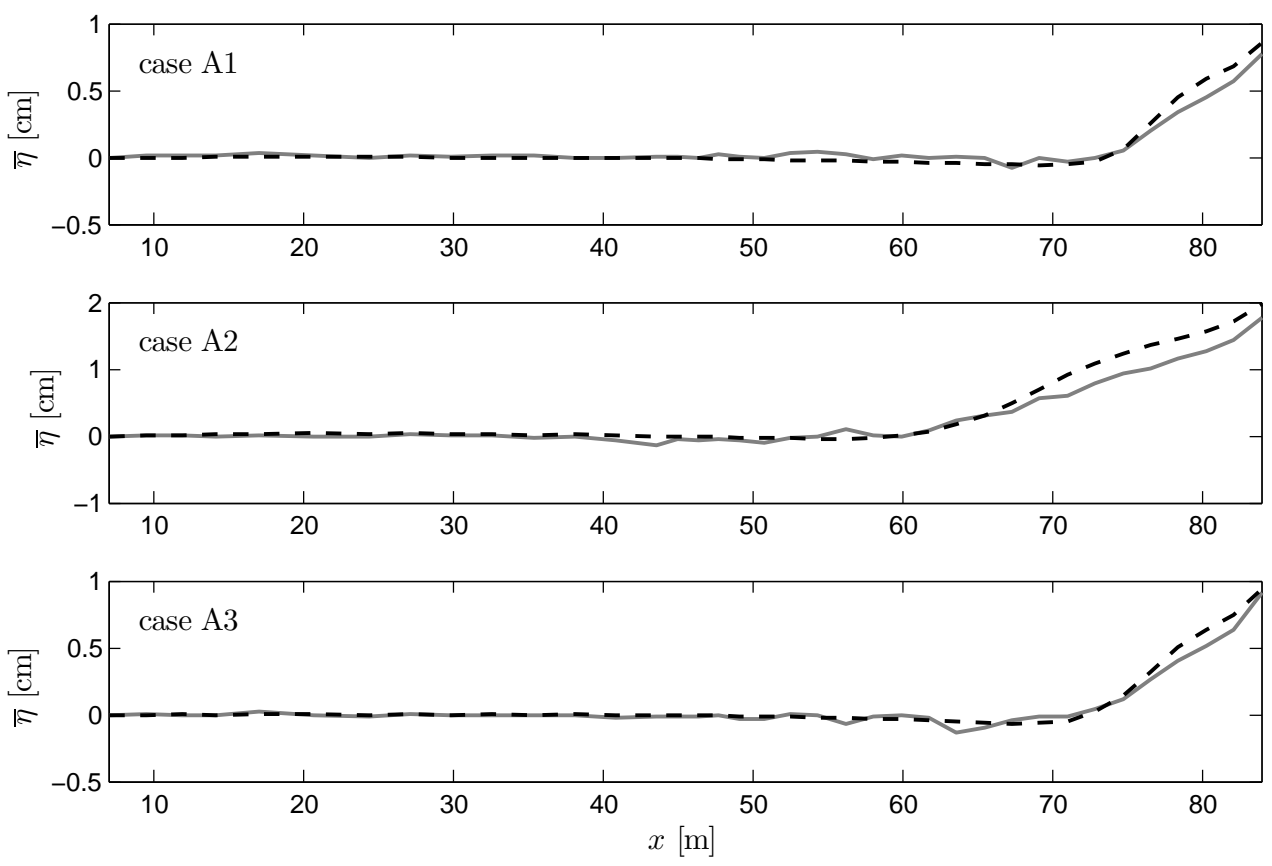

Figure 4: Comparisons between the measured (grey solid line) and simulated (black dashed line) cross-shore variation of mean set-up.

Observation of figure 3 makes manifest the strong nonlinearity which characterize shoaling and breaking waves over the varying bathymetry. The 
wave nonlinearity can be estimated by means of skewness and asymmetry which are statistical parameters indicating the asymmetry of the wave shape with respect to the horizontal and vertical axis, respectively. They are important parameters playing a fundamental role in driving bed shear stresses and thus cross-shore sediment fluxes (Nielsen, 1992; Abreu et al., 2013). Figure 5 shows the cross-shore evolution of short wave free surface skewness and asymmetry for case A3. The short wave component of the free surface $\eta_{h f}$ is obtained by means of a Fourier-filtered high-pass time series with a cut-off frequency of $f_{p} / 2$, in which $f_{p}$ denotes the peak frequency of the irregular wave case. Wave skewness $S k$ and asymmetry $A s$ are calculated as (Elgar and Guza, 1985):

$$
\begin{gathered}
S k=\frac{\overline{\Re(\mathcal{H})^{3}}}{\left(\overline{\eta_{h f}^{2}}\right)^{1.5}}=\frac{\overline{\eta_{h f}^{3}}}{\left(\overline{\eta_{h f}^{2}}\right)^{1.5}} \\
A s=\frac{\overline{\Im(\mathcal{H})^{3}}}{\left(\overline{\eta_{h f}^{2}}\right)^{1.5}}
\end{gathered}
$$

where $\Re(\mathcal{H})$ and $\Im(\mathcal{H})$ denote the real and the imaginary part of the Hilbert transform of $\eta_{h f}$. These parameters represent higher-order moments which are expected to increase for near-breaking waves. Note that skewness takes positive values for waves with sharp crests and flat, broad troughs whereas waves with the forward face steeper than the rear face are characterized by negative asymmetry. Over the horizontal bottom region up to the toe of the beach $(x=16.57 \mathrm{~m})$, nonlinear waves have a positive skewness and negligible asymmetry being symmetrical about a vertical axis, as in Stokes waves. Over the sloping bottom, the relatively small values of short wave skewness increase to reach a first local maximum slightly shoreward of the breaking point. Here the breakpoint $x_{b}$ is defined as the point where $\left(H_{s} / H_{s 0}\right)^{2}=0.75, H_{s 0}$ being the offshore significant wave height. Inside the surf zone, short waves are likely to tend to a sawtooth shape thus reducing their skewness. The short wave asymmetry is negligible up to the toe of the beach and then it decreases as depth decreases as a result of the characteristic pitched-forward shape of shoaling and breaking waves (see Rocha et al. (2013) for more details). The model accurately reproduces the cross-shore evolution of both skewness and asymmetry.

Figure 6 presents the comparison of the computed run-up oscillations with measured data. Since the run-up wire was placed at $0.8 \mathrm{~cm}$ above the bottom, the model run-up toe location is defined here as the most shoreward 

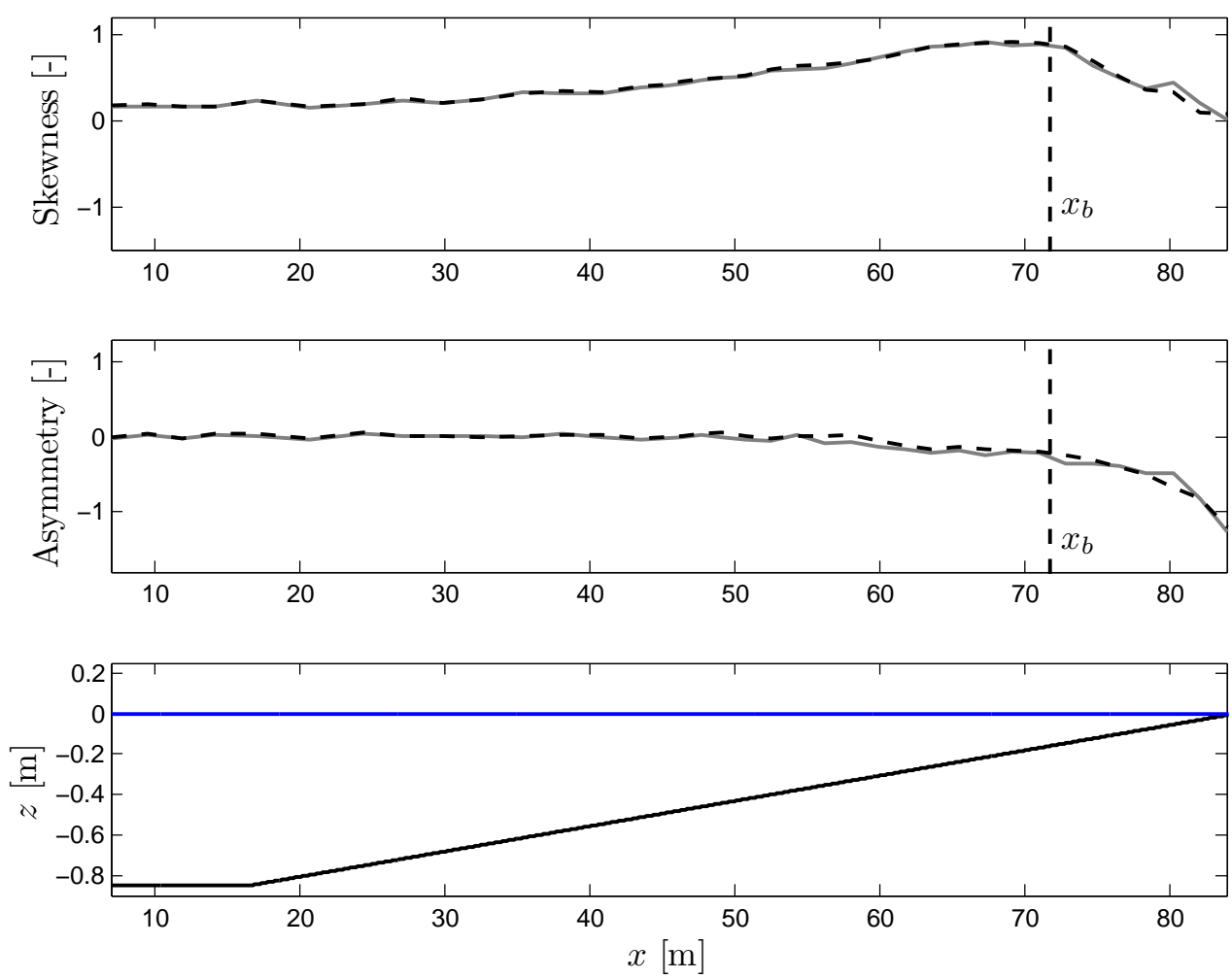

Figure 5: Cross-shore variation of measured (grey line) and simulated (black dashed line) high-frequency wave skewness and asymmetry for case A3. Lower panel: bottom profile.

location where water depth exceeds $0.8 \mathrm{~cm}$. Field studies have shown that run-up statistics are related to the minimum water elevation chosen for the definition of the time-varying shoreline position. Raubenheimer and Guza (1996) measured run-up with a vertical stack of five parallel wires at different elevations between 5 and $25 \mathrm{~cm}$ above the beach face. They pointed out that as the minimum elevation increases, low-frequency energy decreases and seaswell energy increases. Time series of predicted and measured run-up are shown in the left panels of figure 6 for cases A1, A2 and A3. The agreement of computed results with laboratory data is satisfactory. The run-up relative error is obtained as the difference between the computed $S_{m}$ and the observed $S_{l}$ significant run-up, divided by $S_{l}$ :

$$
E(\%)=\left|\frac{S_{m}-S_{l}}{S_{l}}\right| \cdot 100
$$


in which the significant run-up $S$ is estimated from the swash energy spectra $E(f)$ taking into account both infragravity and incident frequencies:

$$
S=4 \sqrt{\sum_{f_{1}}^{f_{2}} E(f) d f}
$$

For cases A1, A2 and A3 the run-up relative errors takes the values of 11 $\%, 5 \%$ and $1 \%$, respectively. The time instants at which maximum runup events occur are well captured, albeit with small differences in absolute maximum run-up. The backwash evolution is accurately predicted as well as the absolute values and the time instants of minimum run-up when incoming bores catch and interact with the preceding run-up. Some minor discrepancies can be noted in correspondence of maximum run-up events for case A2; in particular during the backwash, when water runs-down uncovering the beach face, which appears to occur faster in the model. This difference is possibly due to a temporal variability in the friction factor $c_{f}$ (Puleo and Holland, 2001; Puleo et al., 2012) which is not accounted for in the model where a constant $c_{f}$ is used. The right panels of figure 6 shows the computed and measured run-up spectra. In agreement with laboratory observations, no significant peak is observed in correspondence to the offshore frequency peak. The predicted run-up spectra is saturated in the entire sea-swell frequency band with the saturated region extending in the infragravity band towards lower frequencies for the most energetic case A2. The $f^{-3}$ spectral decay of the saturated region is well reproduced by the model with most of energy concentrated in the lowest frequencies of the infragravity band. This value of the spectral decay is consistent with the field observations collected by Ruessink et al. (1998) under dissipative conditions. The relative discrepancy between the observed and simulated significant run-up is in the order of 10 $\%$ for case A1 and lower than 10\% for A2 and A3 cases. In general terms, the run-up is predicted well by the model.

Despite the minor discrepancies with laboratory observations, the model has proven to satisfactorily reproduce the main hydrodynamic processes induced by breaking waves in the surf and swash zone. The provided validation attests the model ability to quantitatively study wave transformation and run-up over the gently sloping beach considered in this work. 

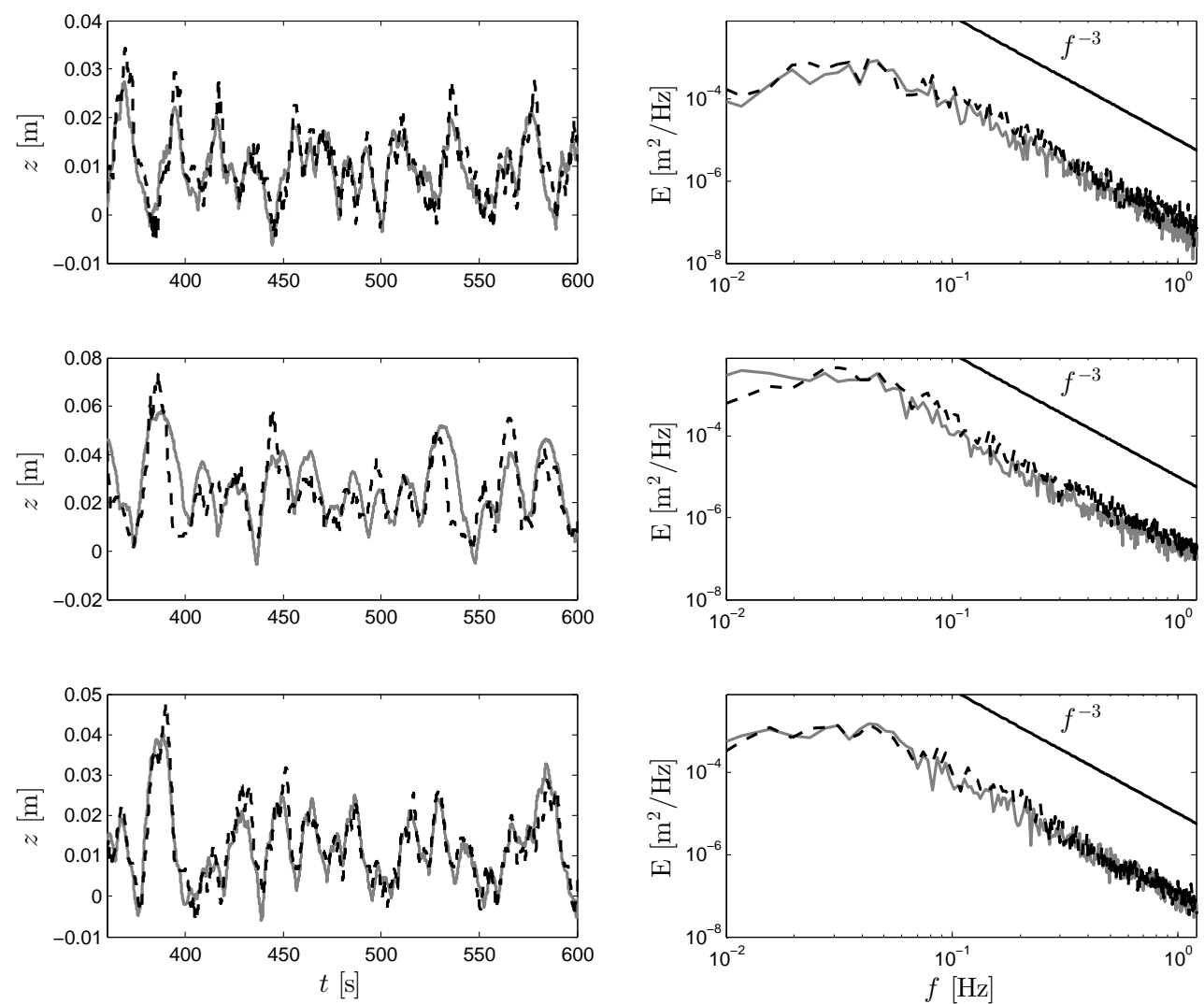

Figure 6: Comparisons between the measured (grey solid line) and simulated (black dashed line) swash oscillations. Left panels: time series; right panels: energy spectra. Upper panels: case A1; mid panels: case A2; lower panels: case A3.

\section{Numerical analysis}

Field studies demonstrated that run-up measurements are sensitive to the wire elevation owing to the thin water tongue which flows below the wire (Raubenheimer and Guza, 1996). In the validation section, the run-up toe location has been defined in the model according to the wire elevation. Here, the predicted run-up statistics are compared for different minimum water level elevations. Figure 7 shows energy spectra of run-up for case A3 corresponding to 3 and $8 \mathrm{~mm}$ minimum water elevation. Only minimal changes can be found in the saturated incident band where the spectral decay is roughly constant. The low-frequency part of the spectra is clearly 
sensitive to the run-up toe definition. The significant run-up corresponding to $3 \mathrm{~mm}$ minimum water elevation is $35 \%$ larger than that obtained with a water elevation of $8 \mathrm{~mm}$. This result is consistent with the experiments of Raubenheimer and Guza (1996) who found that in the field the differences in significant run-up are of the order of $30 \%$ between $5 \mathrm{~cm}$ and $15 \mathrm{~cm}$ elevations. It is important to remark that, video observations correspond closely to a 5 cm minimum elevation (Holland et al., 1995; Guza and Feddersen, 2012). In order to compare the present numerical data with existing field data and parameterizations, in this section the run-up location is defined as the point where the fluid thickness exceeds $0.3 \mathrm{~cm}$. Due to the geometrical scale 1:20 adopted, this value is equivalent to $6 \mathrm{~cm}$ in the prototype which is the wire elevation that brings the best comparisons with video measurements.

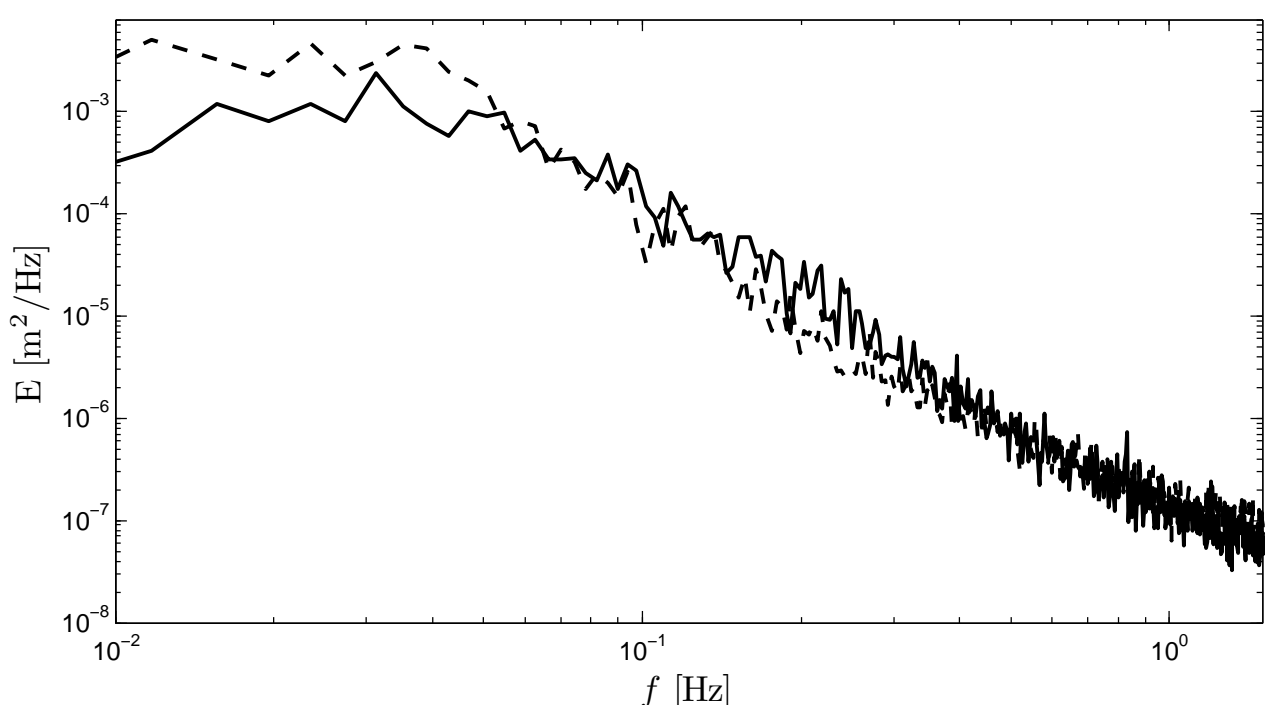

Figure 7: Energy spectra of swash oscillations for different minimum water depth $d$. Solid line: $d=8 \mathrm{~mm}$; dashed line: $d=3 \mathrm{~mm}$.

Once the run-up location has been set, the numerical model is applied here for the study of run-up oscillations under high-energetic offshore wave conditions. The number of wave cases analyzed is increased with respect to the laboratory experiments. The run-up variability induced by a relatively wide range of incoming conditions is addressed. This allows the identification of the influence of incoming wave height and period on swash parameters such as the significant run-up and the main run-up frequency. In particular, 
the new set of simulations is designed in order to investigate the potential role played by saturation in limiting the growth of significant run-up under dissipative conditions.

Data from 18 new random-wave numerical simulations are examined. These cases are subdivided into two series, series E and series F, characterized by the peak periods of laboratory cases A1 and A2, respectively. The working depth $h$ in the generation region is kept at $0.85 \mathrm{~m}$ bringing a ratio $h / L$ equal to 0.24 and 0.15 for series $\mathrm{E}$ and $\mathrm{F}$, respectively (implying that waves are generated in intermediate waters). The significant wave height at the generating boundary is varied providing offshore wave steepness $H_{s 0} / L_{0}$, calculated from linear theory using the peak frequency $f_{p}$, between 0.01 and 0.03. These values of $H_{s 0} / L_{0}$ are chosen to match field observation (Senechal et al., 2011). The Ursell number in the generation region varies between 0.7 and 2.2 for series E and between 4 and 12 for series F. The Ursell number $U_{r}$ is defined as:

$$
U_{r}=\frac{H_{s} L^{2}}{h^{3}}
$$

The simulated wave cases with the corresponding Ursell number $U_{r}$ in the generation region, the offshore wave steepness $H_{s 0} / L_{0}$ and the Iribarren number $\xi_{0}$ are summarized in table 2 .

The component sequences of the primary wave band of the irregular-wave numerical simulations of series $\mathrm{E}$ and $\mathrm{F}$ are extracted by mens of Fourier transforms of the first $1500 \mathrm{~s}$ of the first order target free surface signal of cases A1 and A2. The Fourier amplitudes of wave components are determined simply multiplying the target laboratory amplitudes by the ratio between the desired significant wave height and the target significant wave height of the laboratory case. The same phase and frequency sequences are used in order to conserve the structure of the wave groups (Baldock and Huntley, 2002). Therefore, the first order surface elevation $\eta$ at the boundary is calculated as:

$$
\eta(t)=\sum_{n=1}^{N} \frac{H_{s}}{H_{s T}} a_{n} \cos \left(-\omega_{n} t-\phi_{n}\right)
$$

where $a_{n}, \omega_{n}$ and $\phi_{n}$ are the amplitude, radian frequency and phase of the $n$-th wave component, $H_{s}$ is the object significant wave height and $H_{s T}$ is the target significant wave height in the laboratory which is set to 0.1 and $0.2 \mathrm{~m}$ for cases $\mathrm{A} 1$ and A2, respectively.

In order to minimize incoming free long waves, the boundary conditions 


\begin{tabular}{cccccc}
\hline Case & $T_{p}[\mathrm{~s}]$ & $H_{s}[\mathrm{~m}]$ & $H_{s 0} / L_{0}$ & $U_{r}$ & $\xi_{0}$ \\
\hline E1 & 1.58 & 0.036 & 0.010 & 0.74 & 0.124 \\
E2 & 1.58 & 0.045 & 0.013 & 0.92 & 0.111 \\
E3 & 1.58 & 0.055 & 0.015 & 1.11 & 0.102 \\
E4 & 1.58 & 0.064 & 0.018 & 1.29 & 0.093 \\
E5 & 1.58 & 0.073 & 0.020 & 1.48 & 0.088 \\
E6 & 1.58 & 0.082 & 0.023 & 1.66 & 0.082 \\
E7 & 1.58 & 0.091 & 0.025 & 1.85 & 0.079 \\
E8 & 1.58 & 0.100 & 0.028 & 2.03 & 0.075 \\
E9 & 1.58 & 0.109 & 0.030 & 2.22 & 0.072 \\
F1 & 2.25 & 0.074 & 0.010 & 4 & 0.124 \\
F2 & 2.25 & 0.092 & 0.013 & 5 & 0.111 \\
F3 & 2.25 & 0.111 & 0.015 & 6 & 0.102 \\
F4 & 2.25 & 0.129 & 0.018 & 7 & 0.093 \\
F5 & 2.25 & 0.148 & 0.020 & 8 & 0.088 \\
F6 & 2.25 & 0.166 & 0.023 & 9 & 0.082 \\
F7 & 2.25 & 0.185 & 0.025 & 10 & 0.079 \\
F8 & 2.25 & 0.203 & 0.028 & 11 & 0.075 \\
F9 & 2.25 & 0.222 & 0.030 & 12 & 0.072 \\
\hline
\end{tabular}

Table 2: Simulated wave cases 
for the numerical model are provided by a second order wave signal. The Longuet-Higgins and Stewart (1960) theory is used to calculate the secondary waves arising from the sum and difference interactions between wave components of the primary frequency band. Moreover, active wave absorption is turned on allowing outgoing long waves to leave the computational domain without the reflection at the offshore boundary. Each simulation is $1400 \mathrm{~s}$ long.
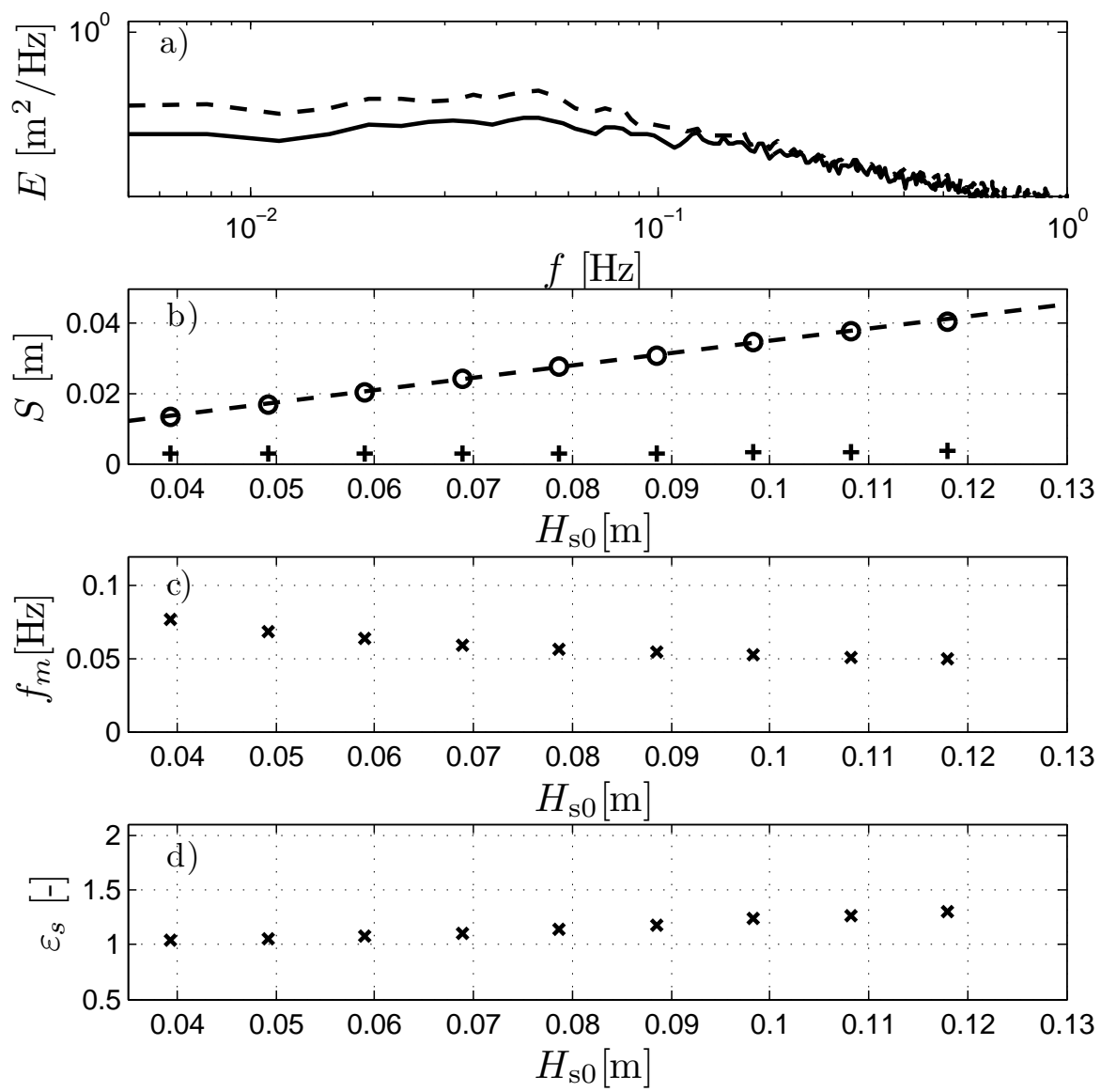

Figure 8: Run-up parameters, series E. a) energy spectra of swash oscillations for cases E1 (solid line) and E9 (dashed line); b) significant run-up elevation $S$ versus offshore wave height $H_{s 0}$ for incident (pluses) and infragravity (circles) components; c) $f_{m}$ versus offshore wave height $H_{s 0} ;$ d) $\varepsilon_{s}$ versus offshore wave height $H_{s 0}$. 

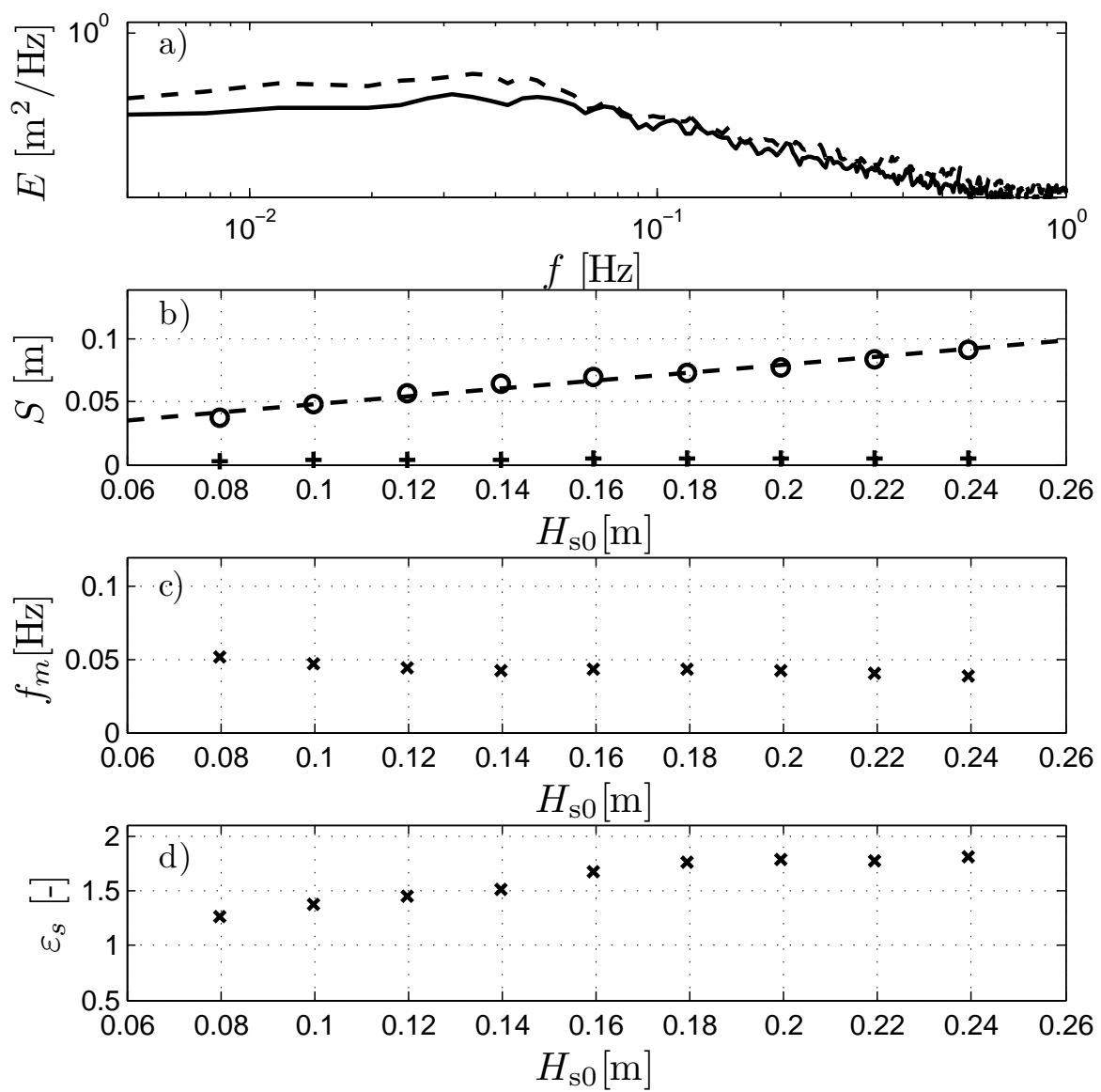

Figure 9: Run-up parameters, series F. a) energy spectra of swash oscillations for cases F1 (solid line) and F9 (dashed line); b) significant run-up elevation $S$ versus offshore wave height $H_{s 0}$ for incident (pluses) and infragravity (circles) components; c) $f_{m}$ versus offshore wave height $H_{s 0} ;$ d) $\varepsilon_{s}$ versus offshore wave height $H_{s 0}$.

Figure 8 shows the run-up parameters for series E. The energy spectra of swash oscillations for the least and most energetic cases E1 and E9 is displayed in the upper panel of figure 8. Saturation yields comparable spectral values for the incident frequency band whereas considerable differences are observed for lower frequency bands where an energy increase occurs for increasing offshore wave energy. The significant run-up elevation $S$ versus offshore wave height $H_{s 0}$ is plotted in figure $8 \mathrm{~b} . S$ is estimated from the swash energy spectra $E(f)$ and is divided into low-frequency $S_{l f}$ and incident $S_{h f}$ 
components:

$$
\begin{aligned}
& S_{l f}=4 \sqrt{\sum_{f_{1}}^{f_{c}} E(f) d f} \\
& S_{h f}=4 \sqrt{\sum_{f_{c}}^{f_{2}} E(f) d f}
\end{aligned}
$$

for $f_{1}=d f \mathrm{~Hz}, f_{c}=f_{p} / 2$ and $f_{2}=3 f_{p}$. Figure $8 \mathrm{~b}$ shows that the run-up levels at high frequency are approximately constant regardless of offshore wave height, consistent with the saturation already commented for spectral estimates. On the other hand, an almost linear dependence of low-frequency significant run-up upon offshore wave height is observed for series E. Even for larger offshore wave steepness, when conditions become more energetic, the increase is still roughly linear suggesting that low-frequency saturation does not take place for series E cases. The slope of the best linear fit is 0.35 (with a correlation coefficient $r$ equal to 0.996 ); this value is in close agreement with that found by Ruggiero et al. (2004) on a natural gently sloping beach. Figure $8 \mathrm{c}$ illustrates the dependence of $f_{m}$ versus offshore significant wave height. $f_{m}$ is the mean frequency of run-up calculated as:

$$
f_{m}=\frac{\sum_{f_{1}}^{f_{2}} f E(f) d f}{\sum_{f_{1}}^{f_{2}} E(f) d f}
$$

for $f_{1}=d f \mathrm{~Hz}$ and $f_{2}=3 f_{p} \mathrm{~Hz}, E(f)$ being the run-up spectral energy spectra. In this panel can be observed that $f_{m}$ drops from 0.08 to 0.05 $\mathrm{Hz}$ across cases E1 and E9. The nondimensional of the non-dimensional parameter $\varepsilon_{s}$ (Carrier and Greenspan, 1958) on $H_{s 0}$ is shown in figure 8d. The $\varepsilon_{s}$ definition originally formulated for regular waves is adapted here by replacing the amplitude of the shoreline motion by the significant run-up $S$ and the regular frequency by $f_{m}$ :

$$
\varepsilon_{s}=\frac{2 S\left(\pi f_{m}\right)^{2}}{\beta^{2} g}
$$

in which $S$ includes the same frequencies considered in equation 17 . For series $\mathrm{E}, \varepsilon_{s}$ monotonically increases from the minimum value of 1.04 for case E1 to the maximum of 1.30 for case E9. 
Data from series $\mathrm{F}$ are illustrated in figure 9. Series $\mathrm{F}$ is characterized by larger peak periods than series E; moreover, nonlinearity of waves is higher as indicated by the large $U_{r}$ numbers. The upper panel of figure 9a illustrates the run-up spectra for the least and most energetic cases F1 and F9. As for series E, saturation of sea-swell frequency takes place and the large variability in swash energy occurs at infragravity frequencies. However, in contrast to figure 8, the saturated part extends to much lower frequencies in series $\mathrm{F}$ than in series E, involving most of the surf beat band. For energetic conditions the change in slope between the saturated and unsaturated part of the spectrum shifts to lower frequencies narrowing the bandwidth of the unsaturated part of the spectrum which is constituted by the only frequency components able to receive additional energy. In figure $9 \mathrm{~b}$, the significant run-up elevation $S$ follows an almost linear increase with the offshore wave height $H_{s 0}$. The correlation coefficient $r$ is relatively high $\left(r^{2}=0.989\right)$ for these cases and the slope of the best linear fit is 0.32 . The mean frequency displayed in figure $9 \mathrm{c}$ decreases from 0.051 to $0.039 \mathrm{~Hz}$. From the observation of figure 9 d, it can be noted that series $\mathrm{F}$ characterized by $\varepsilon_{s}$ ranging between 1.25 and 1.8 shows an increase from case F1 to case F6. In contrast with series E, the monotonic increase of $\varepsilon_{s}$ with $H_{s 0}$ is not observable for the most energetic cases. In fact, it appears that $\varepsilon_{s}$ continues to increase until it reaches a threshold value which for these conditions is about 1.8. The value of 1.8 observed in these simulations appears consistent with the theoretical prediction of Baldock and Holmes (1999) and with laboratory data (Battjes, 1974; Guza and Bowen, 1976). This observed trend mainly reflects the increase of $S$ and the decrease of $f_{m}$ for increasing $H_{s 0}$. In particular, it seems to be strictly related to the energy transfer to long-period run-up oscillations yielding low values of $f_{m}$, which eventually preclude growth of $\varepsilon_{s}$ for the most dissipative conditions considered in this work.

Figure 10 represents the significant infragravity swash elevation $S_{l f}$ versus the dimensional parameter $\sqrt{H_{s 0} L_{0}}$. The dashed line corresponds to the equation proposed by Stockdon et al. (2006):

$$
S_{l f}=0.06 \sqrt{H_{s 0} L_{0}}
$$

Despite the fact that the present data display a small scatter around the Stockdon et al. (2006) predictor, it is important to point out that such formulation is able to satisfactorily address the run-up variability as a function of wave height and period. The small discrepancies can be ascribed to wave 


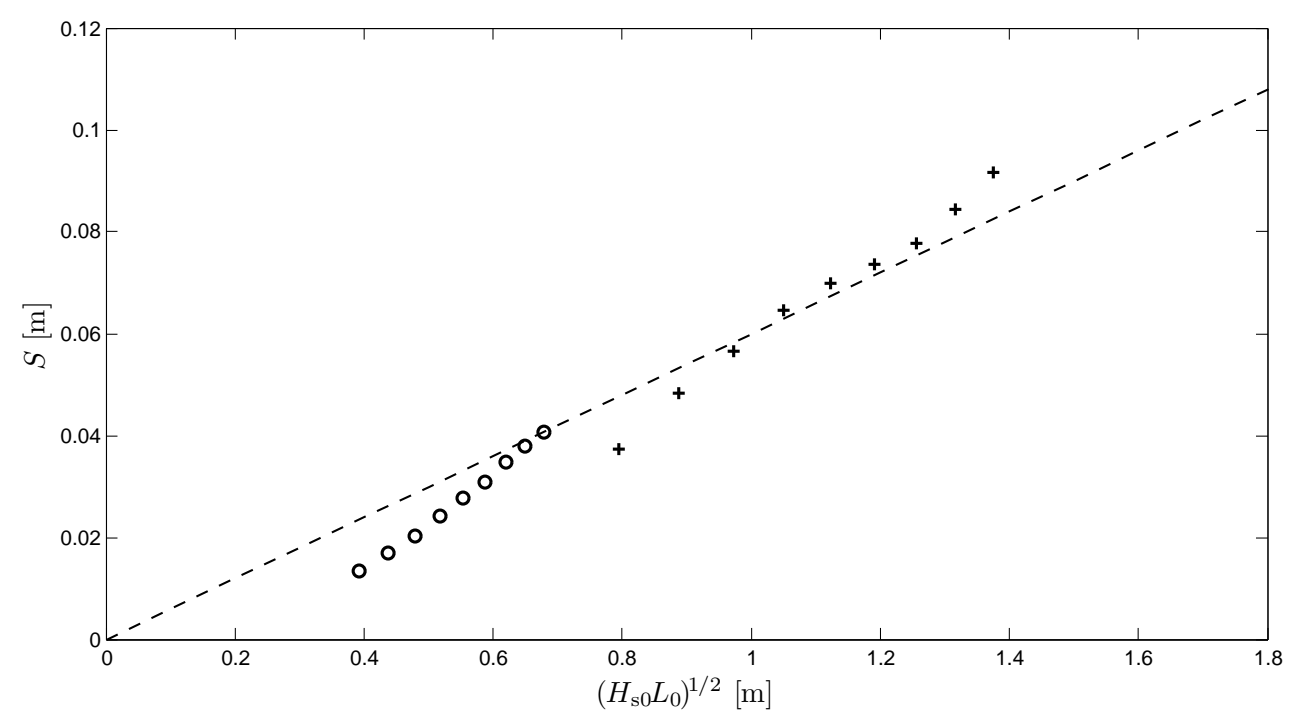

Figure 10: Infragravity run-up elevation parameterized using the dimensional predictor proposed by Stockdon et al. (2006) (dashed line). Circles: series E; pluses: series F.

directional spread and to large scale offshore morphology effects present on natural environments (such as differences between surf and swash zone slopes and sand bars) on run-up variability. Simulated data indicate that run-up variability predictions induced by a wide range of incoming wave conditions are well addressed when both wave height and period are accounted for.

\section{Discussion}

Run-up measurements collected under highly dissipative conditions (Ruessink et al., 1998; Ruggiero et al., 2004) have shown that saturation is likely to extend to frequencies lower than the incident band. Senechal et al. (2011) suggested that saturation of infragravity bands prevents a linear increase of significant run-up for extreme conditions. The results presented here showing a linear increase of run-up amplitude with offshore wave height are in apparent contrast with these findings. However, the present analysis differs from that carried out by Senechal et al. (2011) in a main aspect. In fact, scaling the significant run-up using offshore wave height alone, they reported a run-up growth which almost stops when the offshore wave height exceeds a critical value. On the other hand, in the present study, for a specified 
offshore peak frequency the linear increase of run-up extends over the whole range of the considered offshore wave heights. Therefore, the simulated data suggest that offshore peak frequency plays an important role in determining run-up under dissipative conditions. At the same time, it is worth mentioning that they pointed out that the presence of an upper limit of wave run-up should be investigated under different conditions before their findings can be generalized.

Moreover, it is important to remark that several field investigations (Ruessink et al., 1998; Senechal et al., 2011) fixed a lower limit of the low-frequency band (usually equal to $f=0.004 \mathrm{~Hz}$ ) in order to exclude tides and other very long waves. Since in the present cases swash motions are induced exclusively by the incoming wave field, a lower cutoff frequency for the infragravity band is not adopted. Even in a recent numerical work, Guza and Feddersen (2012) fixed a lower infragravity-band limit for consistency with field investigations. They also pointed out that their results are insensitive to that limit. In the present work, due to the long-period swash motions observed for the most energetic cases, run-up elevations show small (but significant) sensitivity to the choice of such frequency cutoff. In fact, the introduction of a cutoff frequency equal to $0.017 \mathrm{~Hz}$ (which corresponds to the field frequency $0.004 \mathrm{~Hz}$ for the geometrical scale adopted) would reduce the run-up elevations by up to $8 \%$ for the most energetic cases characterized by a mean frequency on the order of $0.04 \mathrm{~Hz}$.

Figures $8 \mathrm{~b}$ and $9 \mathrm{~b}$ suggest that, even though severe sea states lead to narrow unsaturated low-frequency bands, an almost linear increase of runup amplitudes for increasing offshore wave heights is likely to occur even for most energetic conditions. It appears that, as the offshore wave height increases, run-up energy is transferred to lower-frequency motions which are allowed to experience a considerable growth (The order of magnitude of runup energy can be assessed by extending the observed $f^{-3}$ dependence of the saturated band to lower unsaturated frequencies). This energy transfer eventually increases the swash periods consistent with the mean frequency decrease observed in figures $8 \mathrm{c}$ and $9 \mathrm{c}$.

\section{Conclusions}

In this work, run-up variability under dissipative conditions has been investigated by means of numerical modelling. A laboratory dataset has been used to validate the NLSW-type model SWASH. Irregular waves breaking on 
a gently sloping beach and characterized by low Iribarren numbers induced long-period run-up oscillations on the beach face. An $f^{-3}$ spectral decay has been observed in the saturated part of the run-up spectrum.

Comparisons between numerical results and laboratory observations are satisfactory, attesting to the ability of the model of simulating wave transformation along the flume. The breaking and energy dissipation are well addressed. Moreover, the model is able to reproduce the energy transfer leading to the dominance of low-frequency motion in the swash zone.

The model is applied to study the run-up variability under energetic conditions. New numerical simulations extending the conditions considered in the laboratory experiments are carried out. The results show that, for a given peak frequency, the infragravity run-up increases almost linearly with the offshore significant wave height. This is the result of energy transfer towards lower unsaturated frequencies eventually decreasing the mean frequency of run-up oscillations. Moreover, as offshore wave energy increases, the swash similarity parameter $\varepsilon_{s}$ (Miche, 1951; Carrier and Greenspan, 1958) is found to increase, reaching a value of approximately 1.8 in these experiments.

\section{Acknowledgment}

The GLOBEX project, coordinated by Herv Michallet (LEGI, Universit de Grenoble) and Gerben Ruessink (Utrecht University), was supported by the European Community's Seventh Framework Programme through the grant to the budget of the Integrated Infrastructure Initiative Hydralab IV, EC contract no. 261520. The assistance of L. Marcellin (Sogreah-Artelia) in designing the capacitance swash-wire is gratefully acknowledged. The authors wish to thank all other Deltares technicians and staff members for their excellent support during the experiments. Finally, thank you to everybody that was involved in the GLOBEX experiments.

\section{References}

Abreu, T., Michallet, H., Silva, P. A., Shancho, F., van Der A, D. A., Ruessink, B. G., 2013. Bed shear stress under skewed and asymmetric oscillatory flows. Coast. Eng. 73, 1-10.

Baldock, T., 2012. Dissipation of incident forced long waves in the surf zone implications for the concept of bound wave release at short wave breaking. Coast. Eng. 60, 276-285. 
Baldock, T. E., Holmes, P., 1999. Simulation and prediction of swash oscillations on a steep beach. Coast. Eng. 36, 219-242.

Baldock, T. E., Huntley, D. A., 2002. Long-wave forcing by the breaking of random gravity waves on a beach. Proc. Roy. Soc. Lond. A 458, 2177-2201.

Barnes, M. P., Baldock, T., 2010. A lagrangian model for boundary layer growth and bed shear stress in the swash zone. Coast. Eng. 57, 385-396.

Barnes, M. P., O’Donoghue, T., Alsina, J. M., Baldock, T. E., 2009. Direct bed shear stress measurements in bore driven swash. Coast. Eng. 56, 853867.

Battjes, J. A., 1974. Surf similarity. In: Proceedings of the 14th International Conference on Coastal Engineering. ASCE, pp. 466-480.

Battjes, J. A., Bakkenes, H. J., Janssen, T. T., van Dongeren, A. R., 2004. Shoaling of subharmonic gravity waves. J. Geophys. Res. 109 (C18), doi:10.1029/2003JC001863.

Carrier, G. F., Greenspan, H. P., 1958. Water waves of finite amplitude on a sloping beach. J. Fluid Mech. 4, 97-109.

Chow, V. T., 1959. Open-Channel Hydraulics. McGraw-Hill, New York.

de Bakker, A. T. M., Tissier, M. F. S., Marieu, V., Senechal, N., Ruju, A., Lara, J. L., Ruessink, B. G., 2013. Infragravity wave propagation and dissipation on a low-sloping laboratory beach. In: Proceedings of the Conference on Coastal Dynamics.

de Bakker, A. T. M., Tissier, M. F. S., Ruessink, B. G., 2014. Shoreline dissipation of infragravity waves. Cont. Shelf Res. 72, 73-82.

Elgar, S., Guza, R. T., 1985. Observations of bispectra of shoaling surface gravity waves. J. Fluid Mech. 161, 425-448.

Guza, R. T., Bowen, J., 1976. Resonant interactions for waves breaking on a beach. In: Proceedings of the 15th International Conference on Coastal Engineering. ASCE, pp. 560-579.

Guza, R. T., Feddersen, F., 2012. Effect of wave frequency and directional spread on shoreline runup. Geophys. Res. Lett. 39, 111607. 
Guza, R. T., Thornton, E. B., 1982. Swash oscillations on a natural beach. J. Geophys. Res. 87(C1), 483-491.

Henderson, S. M., Bowen, A. J., 2002. Observations of surf beat forcing and dissipation. J. Geophys. Res. 107(C11), doi:10.1029/2000JC000498.

Henderson, S. M., Guza, R. T., Elgar, S., Herbers, T. H. C., Bowen, A. J., 2006. Nonlinear generation and loss of infragravity wave energy. J. Geophys. Res. 111 (C12007), doi:10.1029/2006JC003539.

Herbers, T. H. C., Elgar, S., Guza, R. T., 1995. Generation and propagation of infragravity waves. J. Geophys. Res. 100(C12), 24863-24872.

Holland, K. T., Raubenheimer, B., Guza, R. T., Holman, R. A., 1995. Runup kinematics on a natural beach. J. Geophys. Res. 100(C3), 4985-4993.

Holman, R. A., Sallenger, A. H., 1985. Set-up and swash on a natural beach. J. Geophys. Res. 90, 945-953.

Hughes, M. G., Masselink, G., Brander, R. W., 1997. Flow velocity and sediment transport in the swash zone of a seet beach. Marine Geol. 138, 91-103.

Kikkert, G. A., O’Donoghue, T., Pokrajac, D., Dodd, N., 2011. Experimental study of bore-driven swash hydrodynamics on impermeable rough slopes. Coast. Eng. 60, 149-166.

Longuet-Higgins, M. S., Stewart, R. W., 1960. Changes in the form of short gravity waves on long waves and tidal currents. J. Fluid Mech. 8, 565-583.

Longuet-Higgins, M. S., Stewart, R. W., 1964. Radiation stresses in water waves; a physical discussion, with applications. Deep-sea research and oceanographic abstracts 11, 529-562.

Masselink, G., Hughes, M., 1998. Field investigation of sediment transport in the swash zone. Cont. Shelf Res 18 (10), 1179-1199.

Masselink, G., Puleo, J. A., 2006. Swash-zone morphodynamics. Cont. Shelf Res. 26 (5), 661-680.

Miche, R., 1951. Le pouvoir reflechissant des ouvrages maritimes exposes a 1 action de la houle. Ann. Ponts Chausses 121, 285-319. 
Nielsen, P., 1992. Coastal Bottom Boundary Layers and Sediment Transport. World Scientific.

Nielsen, P., Hanslow, D. J., 1991. Wave runup distributions on natural beaches. Journal of coastal reasearch 7, 1139-1152.

O’Donoghue, T., Pokrajac, D., Hondebrink, L., 2010. Laboratory and numerical study of dambreak-generated swash on impermeable slopes. Coast. Eng. 57, 513-530.

Puleo, J. A., Holland, K. T., 2001. Estimating swash zone friction coefficients on a sandy beach. Coast. Eng. 43, 25-40.

Puleo, J. A., Lanckriet, T., Wang, P., 2012. Near bed cross-shore velocity profiles, bed shear stress and friction on the foreshore of a microtidal beach. Coast. Eng. 68, 6-16.

Raubenheimer, B., Guza, R. T., 1996. Observations and predictions of runup. J. Geophys. Res. 101, 25575-25587.

Raubenheimer, B., Guza, R. T., Elgar, S., Kobayashi, N., 1995. Swash on a gently sloping beach. J. Geophys. Res. 100, 8751-8760.

Rocha, M. V. L., Michallet, H., Silva, P. A., Abreu, T., Barthelemy, E., 2013. Nonlinearities of short and long waves across the shoaling, surf and swash zones: physical model results. In: Proceedings of the Conference on Coastal Dynamics.

Ruessink, B. G., 1998. Bound and free infragravity waves in the nearshore zone under breaking and nonbreaking conditions. J. Geophys. Res. 103, 12795-12805.

Ruessink, B. G., Boers, M., van Geer, P. F. C., de Bakker, A. T. M., Pieterse, A., 2012. Towards a process-based model to predict dune erosion along the Dutch Wadden coast. Netherlands Journal of Geosciences 91-3, 357-372.

Ruessink, B. G., Kleinhans, M. G., van den Beukel, P. G. L., 1998. Observations of swash under highly dissipative conditions. J. Geophys. Res. 103, $3111-3118$. 
Ruessink, B. G., Michallet, H., Bonneton, P., Mouaze, D., Lara, J. L., a. Silva, P., Wellens, P., 2013. Globex: Wave dynamics on a gently sloping laboratory beach. In: Proceedings of the Conference on Coastal Dynamics.

Ruggiero, P., Holman, R. A., Beach, R. A., 2004. Wave run-up on high-energy dissipative beach. J. Geophys. Res. 109 (C06025), doi:10.1029/2003JC002160.

Ruggiero, P., Komar, P. D., Marra, J. J., McDougal, W. G., Beach, R. A., 2001. Wave runup, extreme water levels and the erosion of properties backing beaches. J. Coastal Res. 17, 407-419.

Ruju, A., Lara, J., Losada, I., 2012. Radiation stress and low-frequency energy balance within the surf zone: A numerical approach. Coast. Eng. $68,44-55$.

Senechal, N., Coco, G., Bryant, K. R., Holman, R. A., 2011. Wave run-up during extreme storm conditions. J. Geophys. Res. 116, doi:10.1029/2010JC006819.

Stockdon, H. F., Holman, R. A., Howd, P. A., Sallenger, A. H., 2006. Empirical parameterization of set-up, swash, and run-up. Coast. Eng. 53, 573-588.

Thomson, J. S., Elgar, S., Raubenheimer, B., Herbers, T. H. C., Guza, R. T., 2006. Tidal modulation of infragravity waves via nonlinear energy losses in the surf zone. Geophys. Res. Lett. 33 (L05601), doi:10.1029/2005GL025514.

van Dongeren, A. R., Battjes, J. A., Janssen, T. T., van Noorloos, J., Steenbergen, K., Reniers, A., 2007. Shoaling and shoreline dissipation of low-frequency waves. J. Geophys. Res. 112 (C02011), doi:10.1029/2006JC003701.

van Leewen, P. J., Klopman, G., 1996. A new method for the generation of second-order random waves. Ocean Eng. 23, 167-192.

Zijlema, M., Stelling, G., Smit, P., 2011. Swash: An operational public domain code for simulating wave fields and rapidly varied flows in coastal waters. Coast. Eng. 58, 992-1012. 